\title{
Expression of Ethylene Biosynthesis and Signaling Genes during Differential Abscission Responses of Sweet Orange Leaves and Mature Fruit
}

\author{
Karthik-Joseph John-Karuppiah and Jacqueline K. Burns ${ }^{1}$ \\ University of Florida, IFAS, Horticultural Sciences Department, Citrus Research and Education \\ Center, 700 Experiment Station Road, Lake Alfred, FL 33850
}

\begin{abstract}
Additional Index words. Citrus sinensis, 1-MCP, ethephon, fruit drop, leaf drop, sensitivity
Abstract. When applying abscission agents to tree fruit to facilitate harvest, it is desirable to loosen fruit and not leaves or other organs, but mechanisms controlling leaf and fruit drop are not fully understood. The effect of 450 $\mu L \cdot L^{-1}$ ethephon (ethylene-releasing agent) alone or in combination with 1-methylcyclopropene [1-MCP (ethylene perception inhibitor)] on leaf and mature fruit abscission of 'Valencia' sweet orange (Citrus sinensis) was studied. Leaf abscission increased and fruit detachment force (FDF) decreased significantly especially 4 days after ethephon treatment. Leaf drop rose to over $80 \% 7$ days after application, whereas FDF was only $30 \%$ less than untreated control fruit. When 1-MCP was combined with ethephon and applied to 'Valencia' sweet orange canopies, leaf abscission was greatly reduced, but reduction in FDF proceeded unabated. We hypothesized that differential response of 'Valencia' sweet orange fruit and leaves to 1-MCP was correlated with expression of ethylene biosynthetic and signaling genes and their downstream action. Partial or full-length nucleotide sequences were obtained for 'Valencia' sweet orange homologs of 1-amino-cyclopropane-1-carboxylate synthase-1 (CsACS1), 2 (CsACS2), 1-amino-cyclopropane1-carboxylate oxidase (CsACO), ethylene response sensor-1 (CsERS1), ethylene response-1 (CsETR1), 2 (CsETR2), 3 (CsETR3), constitutive triple response-1 (CsCTR1), ethylene insensitive-2 (CsEIN2), and ethylene insensitive 3-like-1 (CsEIL1) and 2 (CsEIL2). Ethephon application increased expression of biosynthesis genes $C s A C S 1$ and $C s A C O$ and receptors $C s E R S 1$ and $C S E T R 2$ in the abscission zones of leaves and mature fruit. Ethephon-induced increase in gene expression was completely suppressed by $1-\mathrm{MCP}$ application in all but $C s A C S 1$ and $C s A C O$ in fruit abscission zones. Although gene expression was suppressed initially, $C s A C S 1$ and $C s A C O$ expression in fruit abscission zones treated with 1-MCP in the presence or absence of ethephon increased over the 7-day measurement period, suggesting that Cs $A C S 1$ and $C s A C O$ expression were negatively regulated by basal ethylene production in this tissue. However, 1-MCP treatment alone did not loosen fruit, indicating that $C s A C S 1$ and $C s A C O$ played minor roles in fruit abscission. To determine if the difference in ethylene sensitivity was the basis of differential response to ethylene within the same organ, potted 'Valencia' sweet orange plants were treated with ethylene, and rates of blade and petiole drop and detachment forces at the laminar and petiolar abscission zones were studied. Although leaf blades abscised earlier than petioles, the force of detachment was similar, indicating no differences in ethylene sensitivity. Overall, the most significant difference between fruit and leaf abscission zones was seen in the expression of $C s A C S 1$ and $C s A C O$ genes, but the expression pattern was poorly correlated with abscission.
\end{abstract}

Abscission is a coordinated process of separation of organs such as leaves, flowers, and fruit from the parent plant. Abscission occurs in abscission zones due to the dissolution of cell walls by the activity of hydrolase enzymes cellulase and polygalacturonase, resulting in organ detachment. Since the initial work of Horton and Osborne (1967) associating cellulase activity with abscission of bean (Phaseolus vulgaris) explants, cell wall hydrolase activity has been associated with abscission in other plants, including citrus (Citrus spp.) (Greenberg et al., 1975; Ratner et al., 1969). Ethylene is a plant hormone that plays a major role in regulating the abscission process (Bleecker and Patterson, 1997; Burg, 1968; Jackson and Osborne, 1970). Application of exogenous ethylene hastens abscission by inducing expression of cellulase and polygalacturonase genes in peach (Prunus persica) fruit (Bonghi et al., 1992) and tomato (Solanum lycopersicum) leaves, fruit, and flowers (del Campillo and Bennett, 1996; Kalaitzis et al., 1995). In citrus, gene expression and enzymatic activity of cellulase and polygalacturonase increased during ethylene-induced abscission of ma-

Received for publication 20 May 2010. Accepted for publication 8 July 2010. ${ }^{1}$ Corresponding author. E-mail: jkbu@ufl.edu ture citrus fruit (Burns et al., 1998; Greenberg et al., 1975; Huberman and Goren, 1979). The regulatory role of ethylene in abscission was demonstrated in transgenic plants. Overexpressing the ethylene biosynthesis gene 1-aminocyclopropane-1carboxylic acid (ACC) synthase in tomato plants resulted in premature flower abscission, while a delay in abscission was noted in $\mathrm{Nr}$ plants (mutant of ethylene receptor LeETR3) and in plants expressing antisense transcripts of the ethylene receptor LeETR1 (Lanahan et al., 1994; Whitelaw et al., 2002).

The response or sensitivity to ethylene can be controlled at steps involving ethylene biosynthesis and ethylene perception. Ethylene biosynthesis begins with the conversion of S-adenosylmethionine (SAM) to ACC by ACS. ACC is oxidized to ethylene by ACO. The conversion of SAM to ACC by ACS is considered the rate-limiting step in ethylene biosynthesis, but regulation at the ACO step has also been reported (Alexander and Grierson, 2002). The structure of ACS is similar to the subgroup I family of pyridoxal 5' -phosphate (PLP)dependent aminotransferases and PLP is an essential cofactor for ACS activity (Mehta et al., 1993). ACS is encoded by a multigene family and different isoforms are differentially regulated (Barry et al., 2000; Oetiker et al., 1997; Peck and Kende, 
1998). ACO is also encoded by a multigene family, and differential expression of $A C O$ has been observed (Barry et al., 1996; Nakatsuka et al., 1997, 1998).

Ethylene perception begins with ethylene binding at the receptors located in the endoplasmic reticulum (Nehring and Ecker, 2004). Many ethylene perception receptors were elucidated using the triple response of arabidopsis (Arabidopsis thaliana) seedlings when exposed to ethylene. Bleecker et al. (1988) isolated the first ethylene receptor ETR in arabidopsis. Screening for ethylene-insensitive plants using the triple response led to the isolation of four additional ethylene receptors in arabidopsis: ETR2 (Sakai et al., 1998), ERS1 (Hua et al., 1995), ERS2 (Hua et al., 1998), and EIN4 (Hua et al., 1998; Roman et al., 1995). The N-termini of the receptor proteins contain transmembrane domains, with ETR1 and ERS1 having three transmembrane domains and ETR2, ERS2, and EIN4 having four transmembrane domains (Nehring and Ecker, 2004). The C-termini contain histidine kinase and receiver domains and share similarity with the bacterial two-component signal transduction system (Chang et al., 1993). ERS1 and ETR1 receptors have conserved protein motifs in the histidine kinase domain and are classified as subfamily I receptors, whereas subfamily II receptors (ETR2, ERS2, and EIN4) have one or more protein motifs missing. ERS1 and ERS2 do not have the receiver domains. Downstream of the receptors in the signaling pathway is CTR1 (Kieber et al., 1993). CTR1 interacts with the receptors and together they act as negative regulators in ethylene signaling. Downstream of CTR1 is EIN2, which is a positive regulator in ethylene signaling pathway (Alonso et al., 1999). Downstream of EIN2 is EIN3, which is located in the nucleus. EIN3 belongs to a multigene family designated as EIL proteins. EIN3 and EILs are transcription factors that ultimately activate ethylene-responsive genes. Several studies have examined how ethylene treatment impacted expression of these perception and signaling genes in an attempt to identify which may have important roles in downstream biological responses. In general, subfamily I receptors are thought to play a more dominant role in ethylene signaling (Cancel and Larsen, 2002).

Ethephon is an ethylene-releasing compound used to accelerate abscission. Ethephon is an effective abscission agent in citrus, plum (Prunus domestica), cherry (Prunus cerasus), and olive (Olea europaea) (Bukovac et al., 1969; Burns, 2002; Martin et al., 1981). However, excessive leaf abscission occurs at concentrations required for effective fruit loosening in citrus (Burns, 2002) and olive (Burns et al., 2008). Pozo et al. (2004) used 1-MCP, an ethylene perception inhibitor that irreversibly binds to ethylene receptors, to reduce ethephon-induced leaf drop with minimal effect on ethephon-induced fruit loosening. Application of guanfacine, an agonist of G-protein-coupled $\alpha_{2 \mathrm{~A}}$-adrenoreceptors, also reduced ethephon-induced leaf drop but not fruit loosening (Yuan et al., 2005). These data suggest that different abscission control mechanisms may exist in leaf and mature fruit of citrus. Furthermore, ethylene-independent abscission has been observed in several plants. Studies with ethylene-insensitive mutants revealed that ethylene-independent abscission occurs in arabidopsis (Patterson and Bleecker, 2004). Moreover, the lack of ethylene involvement was observed during flower abscission in tulip (Tulipa hybrida) and orchid (Cymbidium sp.) (Sexton et al., 2000; van Doorn, 2002).

For effective use of mechanical harvesting in citrus, it is necessary to use abscission agents that preferentially increase fruit loosening but have very little effect on leaf abscission. Thus, understanding mechanisms of abscission in leaf and mature fruit can provide insight into the abscission process and can assist with selecting an effective abscission compound with uniform efficacy. The objective of this study was to test if differential expression of ethylene biosynthesis and signaling genes were correlated with differential abscission of leaves and mature fruit. In this study, genes involved in ethylene signaling and biosynthetic pathways were cloned from citrus and their expressions were analyzed during abscission in leaf and fruit tissues. We demonstrate that most ethylene biosynthetic and perception gene expression explored in this study were responsive to ethephon application in one or more tissues examined, that failure of 1-MCP to suppress fruit loosening was not correlated with $A C S$ or $A C O$ expression in fruit abscission zones, and that differential timing of subtending organ drop at two spatially distinct leaf abscission zones was not correlated with ethylene sensitivity.

\section{Materials and Methods}

Plant materials and treatment. 'Valencia' sweet orange trees [17 years old on Swingle citrumelo (Citrus paradisi $\times$ Poncirus trifoliata) rootstock] were selected from an experimental grove located at the Citrus Research and Education Center, Lake Alfred, FL. Trees were sprayed until runoff with $450 \mu \mathrm{L} \cdot \mathrm{L}^{-1}$ ethephon or $5 \mathrm{~mm}$ of $1-\mathrm{MCP}$ or a combination of both using a motorized back-pack sprayer on 28 Apr. 2006 as described (Pozo et al., 2004). Control trees were sprayed with water and two trees were used for each treatment. The experiment was repeated on 30 Apr. 2008. Data from the two seasons had similar trends and hence the average from both seasons is shown for leaf drop, fruit detachment force, and gene expression. Leaf abscission and FDF were measured immediately after treatment and after $6 \mathrm{~h}$ and 1, 2, 4, and $7 \mathrm{~d}$ of application. Ten branches (each with about 100 leaves; $\approx 1$ year old) per treatment were tagged to follow leaf abscission. Leaf count was taken on these branches and the percentage of leaf drop was calculated. FDF was measured on five mature fruit (percentage soluble solids/percentage acid ratio of juice was $\approx 15.0$ ) per replication with four replicates using a digital force gauge (Force One; Wagner Instruments, Greenwich, CT).

Reports indicate that abscission may be initiated in organ abscission zones and/or their subtending organs (Alferez et al., 2005; Beyer, 1975), thus leaf blade, laminar abscission zones (LAZ), fruit peel, and fruit abscission zones (FAZ) were used for this study. Samples of leaf blade, LAZ, fruit peel, and FAZ tissues were collected in three replicates during the first season (four replicates during the second season) immediately after treatment and $6 \mathrm{~h}$ and 1, 2, 4, and $7 \mathrm{~d}$ after application. Leaf blade and LAZ were collected from 10 leaves/replicate at each sampling time. Midsection of the leaf blade was used and LAZ were excised using a razor blade as described (Yuan et al., 2005). Fruit peel and FAZ were collected from four fruit/ replicate. Fruit flavedo (the colored portion of the peel) was removed from the equatorial area of each fruit using a potato peeler. FAZ were removed from fruit using a 1-cm-diameter cork borer. The pedicel, calyx, and albedo surrounding the abscission zone were trimmed away using a razor blade, leaving about the 4-mm-thick FAZ intact. Tissues were frozen in liquid nitrogen immediately after sampling and stored at $-80{ }^{\circ} \mathrm{C}$ until needed. 
RNA EXTRACTION. RNA was extracted from $0.5 \mathrm{~g}$ of flavedo, $0.5 \mathrm{~g}$ of leaf blade, four FAZ $(\approx 0.3 \mathrm{~g})$, and $10 \mathrm{LAZ}(\approx 0.2 \mathrm{~g})$. The frozen tissue was ground into fine powder and suspended in $1 \mathrm{~mL}$ of cold TRI Reagent (Molecular Research Center, Cincinnati, OH). Chloroform $(200 \mu \mathrm{L})$ was added and the mixture vortexed thoroughly. Samples were incubated on ice for $15 \mathrm{~min}$ and centrifuged at $20,000 \mathrm{~g}_{\mathrm{n}}$ for $15 \mathrm{~min}$ at $4{ }^{\circ} \mathrm{C}$. RNA was extracted from the aqueous fraction using a RNeasy mini kit (Qiagen, Valencia, CA). First-strand cDNA was synthesized from $1 \mu \mathrm{g}$ of RNA using SuperScript III Reverse Transcriptase (Invitrogen, Carlsbad, CA) in a $20-\mu \mathrm{L}$ reaction.

GeNe ClONING. Full-length nucleotide sequences of four putative ethylene receptors were cloned from leaf blade tissues of 'Valencia' sweet orange. The full-length sequence of CsERS1 (1905 bp) was obtained from the NCBI database (accession no. AF092088). A partial sequence of CSETRI was available in NCBI (accession no. AJ276294) and a full-length sequence (2223 bp; accession no. GQ339592) was amplified using the $5^{\prime}$ RACE and 3' RACE systems (Invitrogen) and cloned. A partial sequence of CsETR2 was available in a citrus mature fruit and leaf EST database (J.K. Burns, unpublished data) and a partial sequence of CsETR 3 was obtained from the publically available citrus HarvEST database (University of California, 2009). Full-length sequences of CsETR2 (2295 bp; accession no. GQ339593) and CsETR3 (2292bp; accession no. GQ339594) were amplified by 5' RACE and 3' RACE protocols and cloned. Partial sequences of CsCTR1, CsEIN2, and CsEIL2 were obtained from HarvEST database. A partial sequence of CSEIL1 was obtained from mature fruit and leaf EST database and 3' RACE protocol was used to amplify and clone the full-length sequence (1845 bp; accession no. GU981740).

GENE EXPRESSION. Primers for real-time polymerase chain reaction (PCR) were designed using Primer Express 3.0 software (Applied Biosystems, Foster City, CA). Primer sequences, primer concentrations used, and amplicon lengths are listed in Table 1. Gene expression was analyzed by realtime PCR (model 7500 Fast Real-Time PCR System; Applied Biosystems) using $2 \times$ SYBR Green PCR master mix sold by the instrument manufacturer. One microliter of cDNA was used in a 20- $\mu \mathrm{L}$ reaction. Glyceraldehyde 3-phosphate dehydrogenase $(C s G A P D H)$ was used as a constitutively expressed gene to normalize the differences in concentration of template that may have occurred in each replicate. CsGAPDH and the genes of interest had similar efficiency of amplification. Relative gene expression was calculated using the comparative $\mathrm{C}_{\mathrm{T}}$ (threshold cycle) method (Livak and Schmittgen, 2001). For each sample, the $\mathrm{C}_{\mathrm{T}}$ value for the gene of interest was subtracted from the $\mathrm{C}_{\mathrm{T}}$ value of $C s G A P D H\left(\Delta \mathrm{C}_{\mathrm{T}}\right) \cdot \Delta \Delta \mathrm{C}_{\mathrm{T}}$ was calculated by subtracting $\Delta \mathrm{C}_{\mathrm{T}}$ of one $\mathrm{T}_{0}$ control replicate from the $\Delta \mathrm{C}_{\mathrm{T}}$ of all individual replications for all treatments at each time point. Relative gene expression was calculated using the equation $2^{-\Delta \Delta C T}$. Dissociation curve generated after the amplification indicated that a single amplicon was produced in each reaction.

ETHYLENE SENSITIVITY IN LEAF ABSCISSION ZONES. Citrus leaves have two abscission zones. One abscission zone is located between the leaf blade and the petiole (LAZ) and the second is located between the petiole and the stem (petiolar abscission zone). When abscission agents are applied, leaf blades first abscise due to abscission processes at the LAZ and later followed by abscission of the petioles due to abscission processes at the petiolar abscission zone. To study differences in ethylene sensitivity of LAZ and petiolar abscission zones during ethylene-induced abscission, two 7-year-old potted 'Valencia' sweet orange trees on Swingle citrumelo rootstock were placed in a closed chamber and treated with $5 \mu \mathrm{L} \cdot \mathrm{L}^{-1}$ ethylene for $88 \mathrm{~h}$. The trees were grown in 12/12-h light/dark cycles (light: 0600-1800 HR; dark: 1800-0600 HR) and were watered daily. The temperature and humidity of the chamber were monitored every 15 min using an automatic data logger (HOBO; Onset Computer Corp., Bourne, MA). Leaf blade and petiole drop were counted twice a day at 1000 and $1800 \mathrm{HR}$ on 20 branches (at least 30 leaves/branch).

In another experiment, two 7-year-old potted 'Valencia' sweet orange trees on Swingle citrumelo rootstock were placed in a chamber with $5 \mu \mathrm{L} \cdot \mathrm{L}^{-1}$ ethylene for $24 \mathrm{~h}$ and then transferred to ethylene-free air. The plants were held under the same light, temperature, and humidity conditions as above.

Table 1. Primer sequences, length of amplicon, and primer concentrations used to assess ethylene biosynthesis and perception gene expression for real-time PCR in Citrus sinensis. The genes are 1-amino-cyclopropane-1-carboxylate synthase 1 (CSACS1) and 2 (CsACS2), 1-aminocyclopropane-1-carboxylate oxidase (CsACO), ethylene response sensor 1 (CsERS1), ethylene response 1 (CsETR1), 2 (CsETR2), and 3 (CsETR3), constitutive triple response 1 (CsCTR1), ethylene insensitive 2 (CsEIN2), ethylene insensitive 3-like 1 (CsEIL1) and 2 (CsEIL2), and glyceraldehyde 3-phosphate dehydrogenase (CsGAPDH).

\begin{tabular}{|c|c|c|c|c|}
\hline Gene & Forward primer & Reverse primer & $\begin{array}{l}\text { Final concn } \\
\text { of each } \\
\text { primer }(\mu \mathrm{M})\end{array}$ & $\begin{array}{l}\text { Length of } \\
\text { amplicon } \\
\text { (bp) }\end{array}$ \\
\hline$C s A C S 1$ & 5'-TTCGAATCCACTAGGCACAACTT-3' & 5'-CAACGCTCGTGAACTTAGGAGA-3' & 0.5 & 140 \\
\hline$C s A C S 2$ & 5'-GATGGCGTTATGGCAAGTGA-3' & 5'-GAGCAATTTCCATCGTCCGA-3' & 0.4 & 134 \\
\hline$C s A C O$ & 5'-AAGATGGCCAGTGGATTGATG-3' & 5'-TCACCGAGGTTGACAACAATG-3' & 0.4 & 61 \\
\hline CsERS1 & 5'-TTGTGGACTGACTCACTTCATAAGC-3' & 5'-ATGACACAAAAGCACAAGCC-3' & 0.4 & 104 \\
\hline CsETR1 & 5'-TCGTCAGCAGAATCCTGTTGG-3' & 5'-GGCCTTAATCTTGCTACTGGACA-3' & 0.8 & 120 \\
\hline CsETR2 & 5'-AACTTCGCCCATCCATTGC-3' & 5'-TCACCGTCAGCTAATAAAACTTGC-3' & 0.4 & 109 \\
\hline CsETR3 & 5'-GGCACAATAGCAAAGAAATTAAGGAG-3' & 5'-CGTGCAAGACCCTGATAGTTAGG-3' & 0.3 & 112 \\
\hline CsCTR1 & 5'-GTGGATGGCACCGGAAGTT-3' & 5'-GAATTTCTCCAAGGTTTTTGCAG-3' & 0.4 & 114 \\
\hline CsEIN2 & 5'-GAAAAGGATGATGATGAAGCAGATT-3' & 5'-GAAGCCGGACCATCAGACAT-3' & 0.2 & 116 \\
\hline CsEIL1 & 5'-ACAGAGCAAGAGTAAGGAATGTGTTG-3' & 5'-TCTTGTGCCCGAGACATCTTC-3' & 0.4 & 90 \\
\hline CsEIL2 & 5'-GGGCTGAAGATGAGCCAAACT-3' & 5' -CATAAGGTGGTTGTTGATTCGGTA-3' & 0.5 & 117 \\
\hline$C s G A P D H$ & 5'-GGAAGGTCAAGATCGGAATCAA-3' & 5'-CGTCCCTCTGCAAGATGACTCT-3' & 0.2 & 75 \\
\hline
\end{tabular}


Leaf blade and petiole drop were counted on six tagged branches (at least 30 leaves/branch) every $12 \mathrm{~h}$ for $84 \mathrm{~h}$. Laminar and petiolar detachment force were measured on 30 leaves every $12 \mathrm{~h}$ using a digital force gauge (DS2-11; Imada, Northbrook, IL).

Statistical analysis. Analysis of variance (ANOVA) was performed using SAS (version 9.1; SAS Institute, Cary, NC). Standard error of the mean was calculated and represented as vertical bars in the figures.

\section{Results}

STRUCTURe OF THE ClONED CITRUS ETHYLENE RECEPTORS. Full-length sequences of CsETR1, CsETR2, and CsETR3 (accession nos. GQ339592, GQ339593, and GQ339594, respectively) were obtained from RNA isolated from 'Valencia' sweet orange. The predicted protein sequence from the longest cDNA open reading frame for CsERS1, CsETR1, CsETR2, and CsETR3 contained 634, 740, 764, and 763 amino acids with calculated molecular weights of $71,83,85$, and $86 \mathrm{kDa}$, respectively. Although CsERS1, CsETR1, and CsETR3 had a predicted $\mathrm{pI}$ of 6.5 , CsETR2 had a higher $\mathrm{pI}$ of 8.0. Based on von Heijne transmembrane prediction (von Heijne, 1992), CsERS1 and CsETR1 contained three transmembrane domains in their N-termini, whereas CsETR2 and CsETR3 had four such domains (Fig. 1). CsERS1 and CsETR1 had histidine kinase domains containing five conserved motifs (H, N, G1, F, and G2). CsETR2 lacked all five conserved motifs in the histidine kinase domain. Only the $\mathrm{H}$ motif was present in the histidine kinase domain of CsETR3. CsETR1, CsETR2, and CsETR3 contained the receiver domain with the conserved aspartate residue. The receiver domain was absent in the C-terminus of CsERS1. A structural comparison between the predicted amino acid sequence of the cloned citrus ethylene receptor genes and arabidopsis and tomato heterologs is presented (Fig. 1).

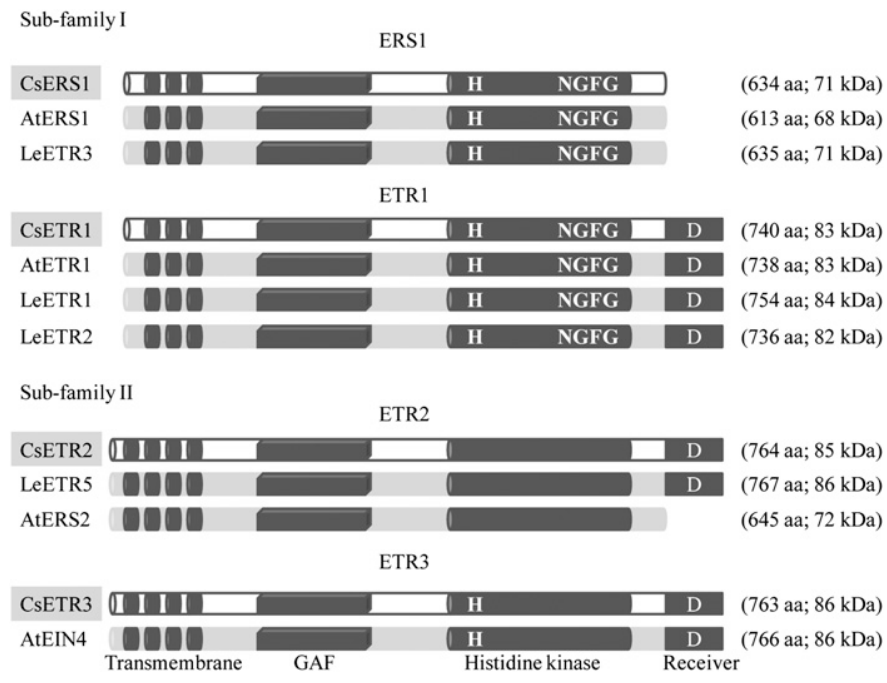

Fig. 1. Comparative schematic representation of Citrus sinensis (Cs), Arabidopsis thaliana (At), and Solanum lycopersicum [Le (formerly Lycopersicon esculentum)] receptors. The number of amino acid (aa) residues and molecular weight of the predicted full-length protein sequences are indicated in parenthesis. The presence of transmembrane domains, GAF domain, conserved $\mathrm{H}$ (histidine), and NGFG (asparagine, glycine, phenylalanine, and glycine, respectively) motifs within the histidine kinase domain and the conserved D (aspartate) residue in the receiver domain are indicated.
Differential EFFECT OF 1-MCP ON LEAF AND FRUIT ABSCISSION. Ethephon-induced leaf abscission was 12\% after $2 \mathrm{~d}$ of application and increased rapidly to $73 \%$ after $4 \mathrm{~d}$ of application (Fig. 2A). When 1-MCP was applied in combination with ethephon, leaf abscission was delayed and reduced to $6 \%$ after $4 \mathrm{~d}$ of application and increased to only $22 \%$ after $7 \mathrm{~d}$. Visual examination for an additional 2 weeks indicated no further increase in leaf abscission in this treatment combination. Fruit loosening was evident $4 \mathrm{~d}$ after ethephon application (Fig. 2B) and FDF was reduced to $6.4 \mathrm{~kg}$ of force compared with $10.5 \mathrm{~kg}$ of force in untreated control fruit. When 1-MCP was combined with ethephon, fruit loosening was reduced slightly on day 2, and FDF fell to $7.8 \mathrm{~kg}$ of force on day 4 after application. However, FDF had fallen to similar levels in both treatments after $7 \mathrm{~d}$ of application. 1-MCP treatment alone did not cause leaf abscission or fruit loosening.

EXPRESSION OF ETHYLENE BIOSYNTHESIS GENES. Expression of CsACS1 in peel was ethylene responsive (Fig. 3A). Peak expression occurred $6 \mathrm{~h}$ after application and then fell to control levels soon thereafter. A slight but measurable increase in gene expression occurred in FAZ $6 \mathrm{~h}$ after ethephon application, but rose 22-fold $24 \mathrm{~h}$ after application and then decreased (Fig. 3B). CsACS1 gene expression in peel was suppressed if 1-MCP was combined with ethephon and applied to the canopy; however, expression in FAZ was only delayed. CsACS1 expression in leaf blade and LAZ tissue was ethephon responsive; with peak expression measured $4 \mathrm{~d}$ after application (Fig. 3, C and D, respectively). Gene expression was suppressed in leaf tissues when 1-MCP was applied in combination with ethephon. Timing of increased CsACS1 gene expression in leaf tissues coincided with increased leaf drop, while in fruit tissues, increased gene expression preceded fruit loosening. Increased expression in FAZ in response to 1-MCP alone suggests that basal ethylene production may be inhibitory to $C S A C S 1$ expression. $C s A C S 2$ expression was
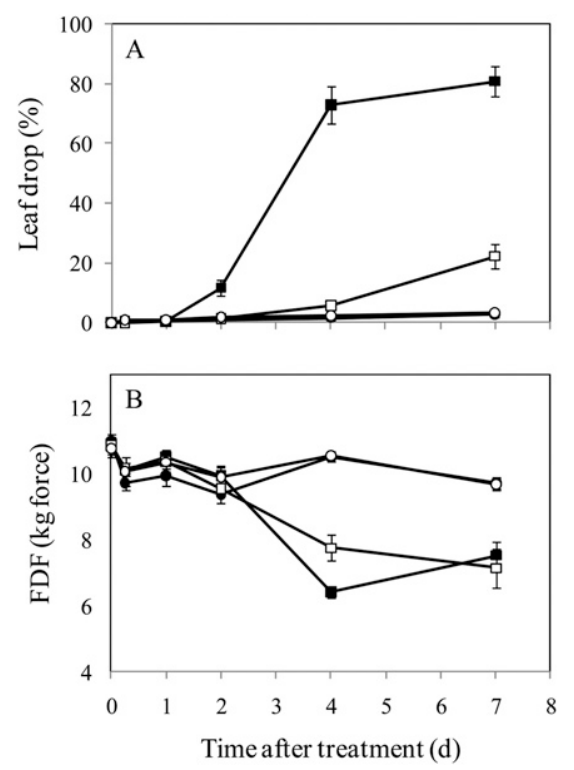

Fig. 2. Percentage of leaf drop (A) and fruit detachment force [FDF (B)] in 'Valencia' sweet orange after treatment with $450 \mu \mathrm{L} \cdot \mathrm{L}^{-1}$ ethephon $(\mathbf{\square}), 5 \mathrm{~mm}$ 1-methylcyclopropene [1-MCP $(\bigcirc)$ ], $450 \mu \mathrm{L} \cdot \mathrm{L}^{-1}$ ethephon $+5 \mathrm{~mm} 1-\mathrm{MCP}$ $(\square)$, or control $(\bullet)$. Vertical bars through symbols represent SE. Where bars are not visible, symbols are larger than SE. 

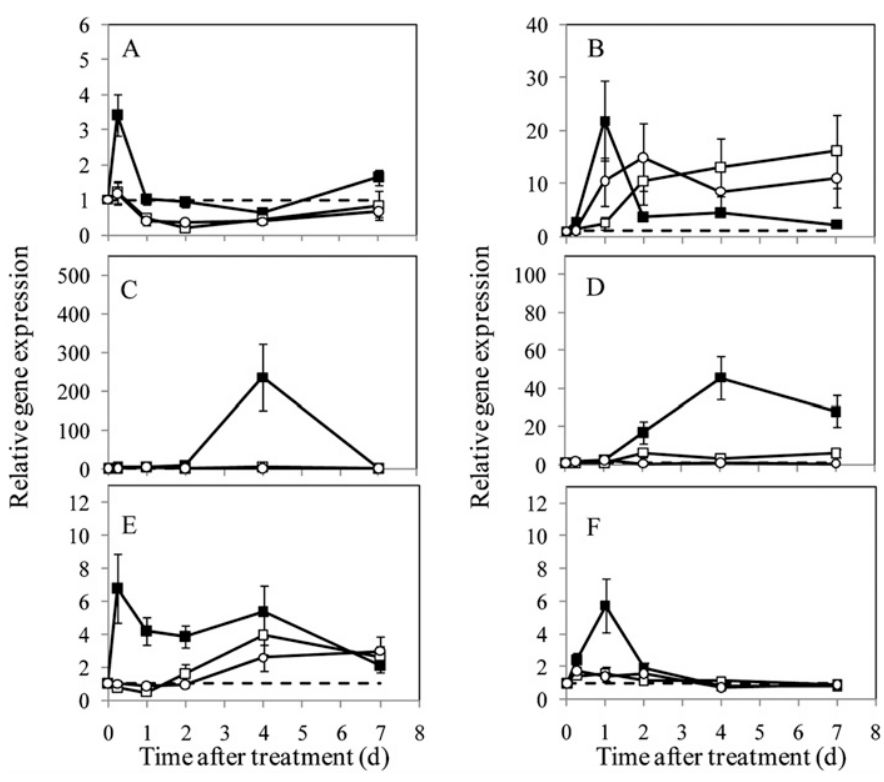

Fig. 3. Gene expression of CsACS1 in fruit peel (A), fruit abscission zone (B), leaf blade (C), and leaf abscission zone (D) and expression of CsACO in fruit abscission zone $(\mathbf{E})$ and leaf abscission zone $(\mathbf{F})$ of 'Valencia' sweet orange. Data represent relative change in gene expression normalized with respect to $\mathrm{T}_{0}$ control (- - ). Trees were treated with $450 \mu \mathrm{L} \cdot \mathrm{L}^{-1}$ ethephon $(\mathbf{\square}), 5 \mathrm{~mm}$ 1-methylcyclopropene [1-MCP $(\bigcirc)$ ], or $450 \mu \mathrm{L} \cdot \mathrm{L}^{-1}$ ethephon $+5 \mathrm{~mm} 1-\mathrm{MCP}$ $(\square)$. Vertical bars through symbols represent SE. Where bars are not visible, symbols are larger than SE.

unaffected by ethephon in any of the four tissues studied (data not shown).

CsACO expression in FAZ reached a maximum (6.8-fold) $6 \mathrm{~h}$ after application of ethephon and remained high through day 4, after which expression decreased (Fig. 3E). Treatments with 1-MCP alone or in combination with ethephon delayed the rise in $C s A C O$ expression. Like $C s A C S 1$ expression, basal ethylene production may inhibit $C s A C O$ expression in FAZ. In LAZ, ethephon treatment increased $C s A C O$ expression, reaching a maximum of 5.7-fold $1 \mathrm{~d}$ after application and then falling to control levels after day 4 (Fig. 3F). Ethephon had very little effect on $C s A C O$ expression in leaf blade and fruit peel (data not shown).

EXPRESSION OF ETHYLENE RECEPTOR AND SIGNALING GENES. CsERS1 was ethylene responsive in all four tissues examined (Fig. 4). In fruit peel (Fig. 4A) and FAZ (Fig. 4B), expression increased to a maximum $6 \mathrm{~h}$ after application and gradually declined to control levels by 4 and $2 \mathrm{~d}$ after application, respectively. CsERS1 expression in response to ethephon increased gradually in leaf blade (Fig. 4C) and LAZ (Fig. 4D) to a maximum of 2.1- and 2.6-fold after 2 and $1 \mathrm{~d}$ of application, respectively. CsETR1 expression was induced by ethephon only in fruit peel where the maximum increase in expression (2.2-fold) occurred after $1 \mathrm{~d}$ of application and decreased to control levels on day 4 (data not shown). Similar to CsERS1, expression of CsETR2 was ethylene responsive in all four tissues (Fig. 5). Ethephon-induced expression in fruit peel, FAZ, and LAZ (Fig. 5, A, B, and D) was higher than control after $6 \mathrm{~h}$ and 1 and $2 \mathrm{~d}$ after treatment and dropped to control levels by day 4 . In leaf blade (Fig. 5C), ethephon induced maximum increase in CsETR2 expression after $1 \mathrm{~d}$ of application and levels in leaf blade remained higher than the control until the end of the experiment. Expression of CSETR3 was unaffected
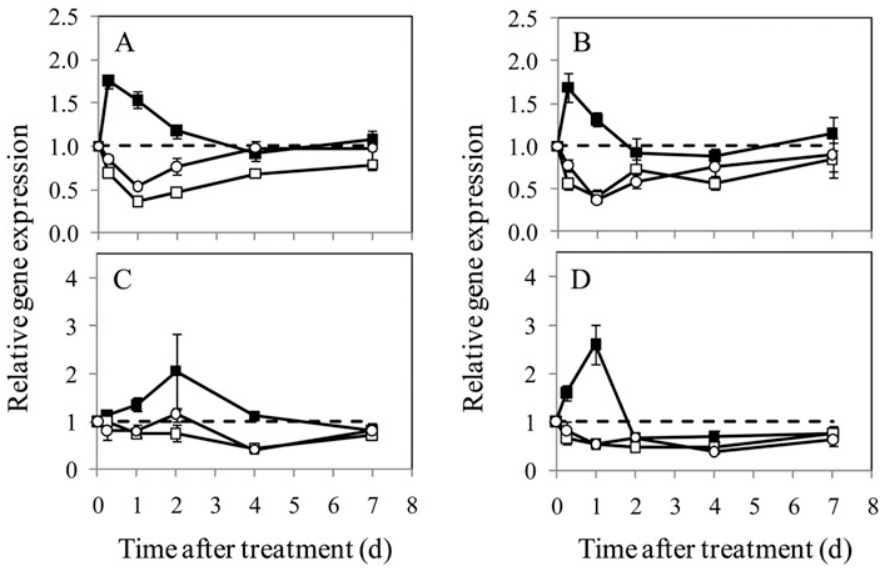

Fig. 4. Gene expression of CsERS1 in fruit peel (A), fruit abscission zone (B), leaf blade (C), and leaf abscission zone (D) of 'Valencia' sweet orange. Data represent relative change in gene expression normalized with respect to $T_{0}$ control (- - -). Trees were treated with $450 \mu \mathrm{L} \cdot \mathrm{L}^{-1}$ ethephon (घ), $5 \mathrm{~mm}$ 1-methylcyclopropene [1-MCP $(\bigcirc)]$, or $450 \mu \mathrm{L} \cdot \mathrm{L}^{-1}$ ethephon $+5 \mathrm{~mm} 1-\mathrm{MCP}$ ( $\square$ ). Vertical bars through symbols represent SE. Where bars are not visible, symbols are larger than SE.
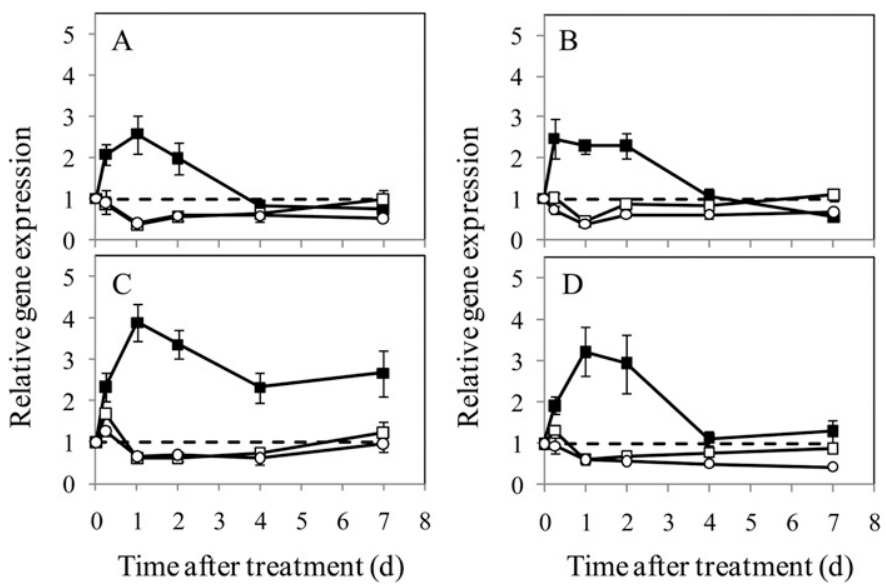

Fig. 5. Gene expression of CSETR2 in fruit peel (A), fruit abscission zone (B), leaf blade (C), and leaf abscission zone (D) of 'Valencia' sweet orange. Data represent relative change in gene expression normalized with respect to $T_{0}$ control (- - -). Trees were treated with $450 \mu \mathrm{L} \cdot \mathrm{L}^{-1}$ ethephon (ם), $5 \mathrm{~mm}$ 1-methylcyclopropene [1-MCP $(\mathrm{O})]$, or $450 \mu \mathrm{L} \cdot \mathrm{L}^{-1}$ ethephon $+5 \mathrm{~mm} 1-\mathrm{MCP}$ ( $\square$ ). Vertical bars through symbols represent SE. Where bars are not visible, symbols are larger than SE.

by ethephon (data not shown). Ethephon-induced increases of receptor gene expression were counteracted by 1-MCP. Expression of CsERS1 and CsETR2 was generally lower than control when 1-MCP was applied alone or in combination with ethephon, while expression of CSETR1 and CsETR3 genes was similar to the control. The expression of CsCTR1, CsEIN2, CSEIL1, and CsEIL2 was variable but not significantly altered by ethephon and/or 1-MCP treatment in any of the tissues (data not shown).

ETHYLENe SENSitivity IN LEAF ABSCISSION zONES. When potted trees were treated with continuous ethylene exposure, abscission of leaf blades was observed $24 \mathrm{~h}$ after exposure, whereas abscission of petioles began after $40 \mathrm{~h}$ (Fig. 6A). Abscission of leaf blades increased rapidly to $95 \%$ after $40 \mathrm{~h}$ of continuous ethylene exposure, and after $64 \mathrm{~h}$, all leaf blades 


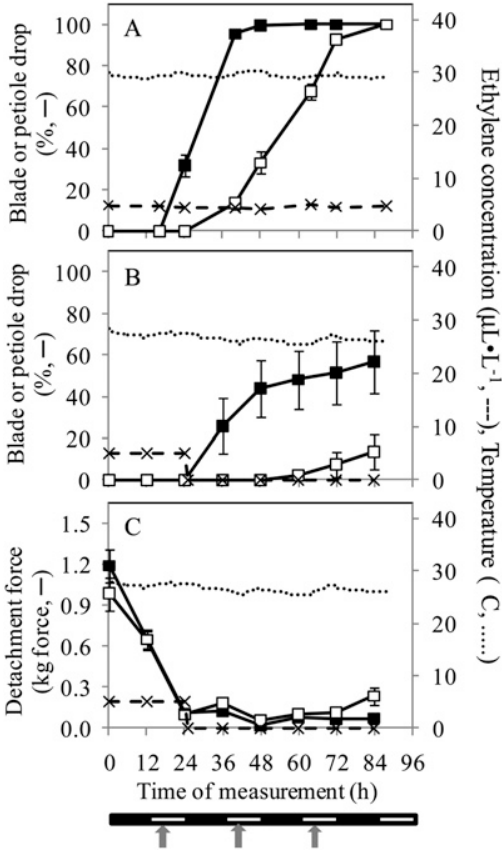

Fig. 6. Percentage of abscission of leaf blade ( $\square$ ) and petiole ( $\square$ ) in 'Valencia' sweet orange when treated with $5 \mu \mathrm{L} \cdot \mathrm{L}^{-1}$ ethylene for $88 \mathrm{~h}(\mathbf{A})$ or $24 \mathrm{~h}$ followed by transfer to ethylene-free air (B). Detachment force $(\mathbf{C})$ of leaf blade and petiole was measured on organs from potted trees treated as in (B). Time of watering is indicated by $\mathbf{\uparrow}$, and white and black bars indicate light and dark conditions, respectively. Vertical bars through symbols represent SE. Where bars are not visible, symbols are larger than SE.

abscised. Abscission of bladeless petioles steadily increased to $93 \%$ by $72 \mathrm{~h}$ and reached $100 \%$ by $88 \mathrm{~h}$. When potted trees were treated with ethylene for $24 \mathrm{~h}$ and then transferred to ethylenefree air, leaf blade abscission began $12 \mathrm{~h}$ after ethylene removal, whereas petioles started to abscise $36 \mathrm{~h}$ after ethylene removal (Fig. 6B). After $60 \mathrm{~h}$ of transfer from ethylene, 57\% and $13 \%$ abscission of leaf blades and petioles was observed, respectively. Leaf blade and petiole detachment forces, however, indicated that reduction in detachment force due to ethylene treatment was similar at both abscission zones (Fig. 6C). The detachment force in both abscission zones reduced from about $1 \mathrm{~kg}$ of force to $0.6 \mathrm{~kg}$ of force at $12 \mathrm{~h}$ and reached a minimum of $0.1 \mathrm{~kg}$ of force by $24 \mathrm{~h}$.

\section{Discussion}

Ethylene receptors are classified into two groups based on conserved motifs present in the histidine kinase domain. Subfamily I receptors contain all conserved motifs in the histidine kinase domain, while subfamily II receptors lack one or more of the conserved motifs. Based on these criteria, CsERS1 and CsETR1 are classified as subfamily I receptors, while CsETR2 and CsETR3 are classified as subfamily II receptors. In arabidopsis, subfamily I receptors play more important roles than subfamily II receptors. Wang et al. (2003) demonstrated that loss of function in the ers 1;etrl double mutant was not compensated by overexpression of any of the three subfamily II receptors. Furthermore, physical interaction between subfamily I receptors and CTR1 was stronger than that of ETR2 (subfamily II) receptor and CTR1, suggesting an important role of subfamily I receptors in ethylene signaling (Cancel and Larsen,
2002). Because an inverse relationship exists between receptor abundance and ethylene sensitivity (Klee, 2004), differences in the abundance of CsERS1 and/or CsETR1 between leaf and fruit tissues could explain differential ethylene sensitivity in these tissues.

CsERS1 is structurally similar to AtERS1 and LeETR3, having three transmembrane domains, all conserved motifs in the histidine kinase domain, and lacking the receiver domain (Fig. 1; Hua et al., 1998; Klee and Tieman, 2002). CsETR1 has three transmembrane domains, a conserved histidine kinase domain, and a receiver domain, which is similar to AtETR1, LeETR1, and LeETR2. CsETR2 and CsETR3 have four transmembrane domains and the receiver domain. CsETR2 lacks all the conserved motifs in the histidine kinase domain, while CsETR3 contains only the H motif. Similar to CsETR2, all the motifs in the histidine kinase domain are absent in AtERS2 and LeETR5, but unlike CsETR2, the receiver domain is absent in AtERS2. CsETR3 is similar to AtEIN4 with four transmembrane domains, only the $\mathrm{H}$ motif in histidine kinase domain, and a receiver domain. Although receptors are redundant, they could have unique functions because they exhibit differential expression patterns in various tissues (Hua et al., 1998; Lashbrook et al., 1998; Tieman and Klee, 1999). Nr (LeETR3) expression increased 10 - to 20 -fold during tomato fruit ripening, and reproductive tissues, flowers, and young developing fruit had higher expression of LeETR4, LeETR5, and LeETR6 when compared with vegetative tissues. CsERS1 and CsETR2 are structurally similar to LeETR3 and LeETR5, respectively, and may play a greater role in ethylene signaling in citrus fruit than in leaves. Furthermore, differences in the levels of different receptors in vegetative and reproductive tissues could result in differential ethylene sensitivity in citrus fruit and leaves.

Citrus leaves and fruit abscised when treated with ethephon, but foliage appeared to respond more readily by dropping over $80 \%$ of the total leaves after $7 \mathrm{~d}$. Apart from this differential intensity of response to ethephon, differential response to 1-MCP was also observed. Ethephon-induced leaf drop was suppressed by application of 1-MCP in combination with ethephon, while it had little effect on fruit loosening. Similar results were observed with application of 1-MCP (Pozo et al., 2004 ) or guanfacine, an agonist of G-protein-coupled $\alpha_{2 A^{-}}$ adrenoreceptors (Yuan et al., 2005). Because 1-MCP is a gas, penetration of 1-MCP into bulky fruit tissues may have been restricted, but less so in leaf tissues. Absorption of 1-MCP was reported to vary between different plant tissues (Nanthachai et al., 2007). These differences were due to various cellular components such as oils, polysaccharides, and lignin that alter 1-MCP absorption. 1-MCP was absorbed faster and in greater amounts in high-lipid avocado (Persea americana) fruit than apple (Malus $\times$ domestica) of lower lipid content (Dauny et al., 2003). Choi and Huber (2009) reported that 1-MCP absorption ranged from $34 \%$ to $94 \%$ in fruit and vegetable tissues, depending on the type of polysaccharide, with xyloglucan exhibiting the lowest absorption (34\%) followed by cellulose $(38 \%)$, starch (49\%), and esterified pectin (94\%). Among the aliphatic components of lipid-derived polymers, citrus leaves contain a higher percentage of fatty alcohols and fatty acids than citrus fruit peel, while peel has a higher percentage of $\omega$-hydroxy acids, dicarboxylic acids, and polar acids than leaves (Espelie et al., 1980). Pectin content was slightly higher in citrus fruit flavedo $\left(270 \mathrm{mg} \cdot \mathrm{g}^{-1}\right.$ dry weight $)$ than in leaf blade (220 mg. $\mathrm{g}^{-1}$ dry weight; H.-L. Liao and J.K. Burns, unpublished 
data). In whole fruit, pectin is expected to be much higher than leaves due to the highly pectinaceous albedo. Nonetheless, our gene expression data indicated that 1-MCP penetrated flavedo and fruit abscission zone tissues sufficiently because ethephoninduced receptor gene expression was suppressed. Thus, differences in oil, polysaccharide, lignin, and pectin content cannot solely account for differential response observed in fruit and leaves.

Alternatively, regeneration of new receptor sites could play a role in the differential abscission response. When ethylene and 1-MCP are coapplied to tissues, 1-MCP preferentially binds to the receptors, but there is no 1-MCP binding preference between receptor types (Hall et al., 2000). Because 1-MCP was applied as a gas to citrus canopies in an open environment, it would be available only for a short duration, while release of ethylene into plant tissues from a liquid ethephon solution could take place after several hours of application (Domir and Foy, 1978; Perry and Gianfagna, 1987). Though more than $50 \%$ of ethephon was dissociated to ethylene within $24 \mathrm{~h}$ of application, ethylene release continued to occur for $96 \mathrm{~h}$ in leaves of tobacco [Nicotiana tabacum (Domir and Foy, 1978)] and peach (Perry and Gianfagna, 1987). Several studies indicated that new receptors were synthesized after 1-MCP was bound to available receptors (Binder et al., 2004; Blankenship and Dole, 2003). In avocado, two applications of 1-MCP at 10-d intervals were required to prevent fruit softening (Pesis et al., 2002), and 1-MCP was effective in increasing vase life of hibiscus (Hibiscus rosa-sinensis) flowers only by continuous exposure for $15 \mathrm{~h}$ (Reid et al., 2002). Application of 1-MCP delayed ripening of avocado and tomato by 2 weeks and 5 to $10 \mathrm{~d}$, respectively (Feng et al., 2000; Wills and $\mathrm{Ku}, 2002)$. If new receptors were synthesized and incorporated into the endoplasmic reticulum, the rate of new receptor regeneration must have varied between tissues. The amount or rate of receptor regeneration in mature citrus fruit could be much lower than in leaves, creating a situation of lower new and functioning receptor numbers in fruit. Because low receptor number is associated with greater ethylene sensitivity (Hua and Meyerowitz, 1998; Klee, 2004; Tieman et al., 2000), residual ethylene released from decaying ethephon could be sufficient to allow fruit loosening to continue.

Although several studies indicated that ethylene plays a major role in accelerating abscission, ethylene is likely not required to initiate the abscission process. Studies in tulip (Sexton et al., 2000), orchids (van Doorn, 2002), and arabidopsis (Patterson and Bleecker, 2004) revealed that ethylene was not necessary for abscission to occur. Patterson and Bleecker (2004) developed five arabidopsis mutants that were ethylene responsive but abscission of floral organs was unaffected by exogenous ethylene. Recently, existence of an alternate signaling pathway for ethylene was hypothesized (Xu et al., 2008). Two FEI proteins (leucine-rich repeat receptorlike kinases) were identified to act in a novel ethylene-signaling pathway during cell wall development in arabidopsis. These proteins were shown to interact directly with ACS proteins, suggesting a potential bypass mechanism leading to ethylene perception-independent ethylene responses. The application of 1-MCP did not prevent ethephon-induced abscission of mature fruit (Fig. 2B). Although it is possible that an ethylene perception-independent pathway leading to responses such as abscission exists in mature citrus fruit, one would have to assume that all receptors were bound by $1-\mathrm{MCP}$. There was no attempt in this study to quantify receptor number or binding of 1-MCP to the receptors, and the presence or operation of a functional ethylene perception-independent pathway that participates in citrus abscission cannot be confirmed or discounted.

Changes in transcript accumulation of ethylene biosynthesis and signaling genes were associated with ethylene responses in citrus (Katz et al., 2004), arabidopsis (Binder et al., 2004), tomato (Barry et al., 2000; Kevany et al., 2007; Wilkinson et al., 1995), plum (Fernández-Otero et al., 2007), carnation [Dianthus caryophyllus (Tanase et al., 2008)], Alstroemeria peruviana (Wagstaff et al., 2005), apple (Dal Cin et al., 2005), and peach (Rasori et al., 2002). CsACS1, CsACO, CsERS1, and CsETR2 expression in fruit peel, leaf blade, and LAZ increased when ethephon was applied and decreased when 1-MCP was combined with ethephon application. In contrast, expression differed in FAZ. Although CsERS1 and CsETR2 expression was suppressed when 1-MCP was combined with ethephon, expression of the biosynthesis genes CsACS1 and $C s A C O$ was only delayed. Moreover, basal ethylene production suppressed gene expression, as application of 1-MCP alone relieved this suppression. Alternatively, saturation of ethylene receptors by $1-\mathrm{MCP}$ may trigger ethylene biosynthesis gene expression in a feedback regulatory mechanism (McCollum and Maul, 2007). Because 1-MCP alone increased expression of biosynthesis genes but did not cause fruit loosening, reduction in FDF was poorly correlated with $C s A C S 1$ and $C s A C O$ gene expression. Increase in expression of CsERS1 and CsETR2 genes is contradictory to the role of ethylene receptors as negative regulators in the signaling pathway. Though these genes were ethylene responsive, gene expression may not correlate with the actual number of active receptor proteins as reported in tomato (Kevany et al., 2007). Expression of CsCTR1, CsEIN2, CsEIL1, and CsEIL2 remained unchanged due to ethephon treatment (data not shown). Post-transcriptional regulation may play a role in citrus as postulated in tomato and arabidopsis (Gao et al., 2003; Guo and Ecker, 2003; Kieber et al., 1993; Klee, 2004; Leclercq et al., 2002; Tieman et al., 2001). Though the mechanism is not clear in CTR1 and EIN2, post-transcriptional regulation of EIN3 and EIL protein was described by Guo and Ecker (2003). Degradation of EIN3 protein occurs through an ubiquitin/proteasome pathway mediated by two $\mathrm{F}$ box proteins, EBF1 (EIN3-binding F box protein 1) and EBF2. This pathway is inactive in the presence of ethylene, resulting in increased accumulation of EIN3 protein. Analyzing the protein expression of CTR1, EIN2, and EILs could help to explain differential abscission responses in citrus.

Taken together, leaves and fruit respond differentially to ethephon and/or 1-MCP. Although differences were seen in timing and intensity of gene expression, the most significant differences were measured in ethylene biosynthesis gene expression in FAZ and LAZ. During the course of this study, it was shown that the timing of ethephon-induced abscission associated with the two abscission zones located in leaves was different. Soon after ethephon application in citrus, the leaf blade abscised first, followed days later by the subtending petiole. However, differences in timing of abscission of the blade and petiole could not be attributed to differences in ethylene sensitivity. Although abscission occurred earlier in the LAZ than the petiolar abscission zone when treated with ethylene, the reduction in detachment force at both locations was similar. Because force is directly proportional to mass (force $=$ mass $\times$ acceleration) and 
the average weights of leaf blade and petiole are 579 and $36 \mathrm{mg}$, respectively, much more downward force was exerted by the leaf blade than by the petiole. The total force exerted by the leaf blade may not be transferred to the petiolar abscission zone due to the presence of the weakened LAZ. This might have caused earlier abscission of the leaf blade at the LAZ than at the petiolar abscission zone. Further work on quantifying the number of receptors in leaf and fruit tissues and the regeneration capacity of receptors would more fully elucidate the basis of this differential abscission response.

\section{Literature Cited}

Alexander, L. and D. Grierson. 2002. Ethylene biosynthesis and action in tomato: A model for climacteric fruit ripening. J. Expt. Bot. 53: 2039-2055.

Alferez, F., S. Singh, A.L. Umbach, B. Hockema, and J.K. Burns. 2005. Citrus abscission and arabidopsis plant decline in response to 5-chloro-3-methyl-4-nitro- $\mathrm{H}$-pyrazole are mediated by lipid signaling. Plant Cell Environ. 28:1436-1449.

Alonso, J.M., T. Hirayama, G. Roman, S. Nourizadeh, and J.R. Ecker. 1999. EIN2, a bifunctional transducer of ethylene and stress responses in arabidopsis. Science 284:2148-2152.

Barry, C.S., B. Blume, M. Bouzayen, W. Cooper, A.J. Hamilton, and D. Grierson. 1996. Differential expression of the 1-aminocyclopropane1-carboxylate oxidase gene family of tomato. Plant J. 9:525-535.

Barry, C.S., M.I. Llop-Tous, and D. Grierson. 2000. The regulation of 1-aminocyclopropane-1-carboxylic acid synthase gene expression during the transition from system-1 to system-2 ethylene synthesis in tomato. Plant Physiol. 123:979-986.

Beyer, E. 1975. Abscission: The initial effect of ethylene is in the leaf blade. Plant Physiol. 55:322-327.

Binder, B.M., R.C. O’Malley, W. Wang, J.M. Moore, B.M. Parks, E.P. Spalding, and A.B. Bleecker. 2004. Arabidopsis seedling growth response and recovery to ethylene. A kinetic analysis. Plant Physiol. 136:2913-2920.

Blankenship, S. and J.M. Dole. 2003. 1-Methylcyclopropene: A review. Postharvest Biol. Technol. 28:1-25.

Bleecker, A.B., M.A. Estelle, C. Somerville, and H. Kende. 1988. Insensitivity to ethylene conferred by a dominant mutation in Arabidopsis thaliana. Science 241:1086-1089.

Bleecker, A.B. and S.E. Patterson. 1997. Last exit: Senescence, abscission and meristem arrest in arabidopsis. Plant Cell 9:1169-1179.

Bonghi, C., N. Rascio, A. Ramina, and G. Casadoro. 1992. Cellulase and polygalacturonase involvement in the abscission of leaf and fruit explants of peach. Plant Mol. Biol. 20:839-848.

Bukovac, M.J., F. Zucconi, R.P. Larsen, and C.D. Kesner. 1969. Chemical promotion of fruit abscission in cherries and plums with special reference to 2-chloroethylphosphonic acid. J. Amer. Soc. Hort. Sci. 94:226-230.

Burns, J.K. 2002. Using molecular biology tools to identify abscission materials in citrus. HortScience 37:15-20.

Burns, J.K., L. Ferguson, K. Glozer, W.H. Krueger, and R.C. Rosecrance. 2008. Screening fruit loosening agents for black ripe processed table olives. HortScience 43:1449-1453.

Burns, J.K., D.J. Lewandowski, C.J. Nairn, and G.E. Brown. 1998. Endo-1,4- $\beta$-glucanase gene expression and cell wall hydrolase activities during abscission in 'Valencia' orange. Physiol. Plant. 102: 217-225.

Burg, S.P. 1968. Ethylene, plant senescence and abscission. Plant Physiol. 43:1503-1511.

Cancel, J.D. and P.B. Larsen. 2002. Loss-of-function mutations in the ethylene receptor ETR1 cause enhanced sensitivity and exaggerated response to ethylene in arabidopsis. Plant Physiol. 129:1557-1567.

Chang, C., S.F. Kwok, A.B. Bleecker, and E.M. Meyerowitz. 1993. Arabidopsis ethylene-response gene ETR1: Similarity of product of two-component regulators. Science 262:539-544.
Choi, S.T. and D.J. Huber. 2009. Differential sorption of 1-methylcyclopropene to fruit and vegetable tissues, storage and cell wall polysaccharides, oil, and lignins. Postharvest Biol. Technol. 52:62-70.

Dal Cin, V., M. Danesin, A. Boschetti, A. Dorigoni, and A. Ramina. 2005. Ethylene biosynthesis and perception in apple fruitlet abscission (Malus domestica L. Borkh.). J. Expt. Bot. 56:2995-3005.

Dauny, P.T., D.C. Joyce, and C. Gamby. 2003. 1-Methylcyclopropene influx and efflux in 'Cox' apple and 'Hass' avocado fruit. Postharvest Biol. Technol. 29:101-105.

del Campillo, E. and A.B. Bennett. 1996. Pedicel breakstrength and cellulase gene expression during tomato flower abscission. Plant Physiol. 111:813-820.

Domir, S.C. and C.L. Foy. 1978. A study of ethylene and $\mathrm{CO}_{2}$ evolution from ethephon in tobacco. Pestic. Biochem. Physiol. 9: $1-8$.

Espelie, K.E., R.W. Davis, and P.E. Kolattukudy. 1980. Composition, ultrastructure and function of the cutin- and suberin-containing layers in the leaf, fruit peel, juice-sac and inner seed coat of grapefruit (Citrus paradisi Macfed.). Planta 149:498-511.

Feng, X., A. Apelbaum, E.C. Sisler, and R. Goren. 2000. Control of ethylene response in avocado fruit with 1-methylcyclopropene. Postharvest Biol. Technol. 20:143-150.

Fernández-Otero, C.I., F. de la Torre, R. Iglesias, M.C. RodríguezGacio, and A.J. Matilla. 2007. Stage- and tissue-expression of genes involved in the biosynthesis and signalling of ethylene in reproductive organs of damson plum (Prunus domestica L. subsp. insititia). Plant Physiol. Biochem. 45:199-208.

Gao, Z., Y.-F. Chen, M.D. Randlett, X.-C. Zhao, J.L. Findell, J.J. Kieber, and G.E. Schaller. 2003. Localization of the Raf-like kinase CTR1 to the endoplasmic reticulum of arabidopsis through participation in ethylene receptor signaling complexes. J. Biol. Chem. 278:34725-34732.

Guo, H. and J.R. Ecker. 2003. Plant responses to ethylene gas are mediated by $\mathrm{SCF}^{\mathrm{EBF} 1 / \mathrm{EBF} 2}$-dependent proteolysis of EIN3 transcription factor. Cell 115:667-677.

Greenberg, J., R. Goren, and J. Riov. 1975. The role of cellulase and polygalacturonase in abscission of young and mature Shamouti orange fruits. Physiol. Plant. 34:1-7.

Hall, A.E., J.L. Findell, G.E. Schaller, E.C. Sisler, and A.B. Bleecker. 2000. Ethylene perception by the ERS1 protein in arabidopsis. Plant Physiol. 123:1449-1457.

Horton, R.F. and D.J. Osborne. 1967. Senescence, abscission and cellulase activity in Phaseolus vulgaris. Nature 214:1086-1088.

Hua, J. and E.M. Meyerowitz. 1998. Ethylene responses are negatively regulated by a receptor gene family in Arabidopsis thaliana. Cell 94: 261-271.

Hua, J., C. Chang, and E.M. Meyerowitz. 1995. Ethylene insensitivity conferred by arabidopsis ERS gene. Science 269:1712-1714.

Hua, J., H. Sakai, S. Nourizadeh, Q.G. Chen, A.B. Bleecker, J.R. Ecker, and E.M. Meyerowitz. 1998. EIN4 and ERS2 are members of the putative ethylene receptor gene family in arabidopsis. Plant Cell 10:1321-1332.

Huberman, M. and R. Goren. 1979. Exo- and endo-cellular cellulase and polygalacturonase in abscission zones of developing orange fruits. Physiol. Plant. 45:189-196.

Jackson, M.B. and D.J. Osborne. 1970. Ethylene, the natural regulator of leaf abscission. Nature 225:1019-1022.

Kalaitzis, P., S.M. Koehler, and M.L. Tucker. 1995. Cloning of a tomato polygalacturonase expressed in abscission. Plant Mol. Biol. 28:647-656.

Katz, E., P.M. Lagunes, J. Riov, D. Weiss, and E.E. Goldschmidt. 2004. Molecular and physiological evidence suggests the existence of a system II-like pathway of ethylene production in non-climacteric Citrus fruit. Planta 219:243-252.

Kevany, B.M., D.M. Tieman, M.G. Taylor, V.D. Cin, and H.J. Klee. 2007. Ethylene receptor degradation controls the timing of ripening in tomato fruit. Plant J. 51:458-467. 
Kieber, J.J., M. Rothenberg, G. Roman, K.A. Feldmann, and J.R. Ecker. 1993. CTR1, a negative regulator of the ethylene response pathway in arabidopsis, encodes a member of the Raf family of protein kinases. Cell 72:427-441.

Klee, H. and D. Tieman. 2002. The tomato ethylene receptor gene family: Form and function. Physiol. Plant. 115:336-341.

Klee, H.J. 2004. Ethylene signal transduction. Moving beyond arabidopsis. Plant Physiol. 135:660-667.

Lanahan, M.B., H.-C. Yen, J.J. Giovannoni, and H.J. Klee. 1994. The Never Ripe mutation blocks ethylene perception in tomato. Plant Cell 6:521-530.

Lashbrook, C., D. Tieman, and H.J. Klee. 1998. Differential regulation of the tomato ETR gene family throughout plant development. Plant J. 15:243-252.

Leclercq, J., L.C. Adams-Phillips, H. Zegzouti, B. Jones, A. Latché, J.J. Giovannoni, J.-C. Pech, and M. Bouzayen. 2002. LeCTR1, a tomato CTR1-like gene, demonstrates ethylene signaling ability in arabidopsis and novel expression patterns in tomato. Plant Physiol. 130:1132-1142.

Livak, K.J. and T.D. Schmittgen. 2001. Analysis of relative gene expression data using real-time quantitative PCR and the $2^{-\Delta \Delta C T}$ method. Methods 25:402-408.

Martin, G.C., S. Lavee, and G.S. Sibbett. 1981. Chemical loosening agents to assist mechanical harvest of olive. J. Amer. Soc. Hort. Sci. 106:325-330.

McCollum, G. and P. Maul. 2007. 1-Methylcyclopropene inhibits degreening but stimulates respiration and ethylene biosynthesis in grapefruit. HortScience 42:120-124.

Mehta, P.K., T.I. Hale, and P. Christen. 1993. Aminotransferases: Demonstration of homology and division into evolutionary subgroups. Eur. J. Biochem. 214:549-561.

Nakatsuka, A., S. Murachi, H. Okunishi, S. Shiomi, R. Nakano, Y. Kubo, and A. Inaba. 1998. Differential expression and internal feedback regulation of 1-aminocyclopropane-1-carboxylate synthase, 1-aminocyclopropane-1-carboxylate oxidase, and ethylene receptor genes in tomato fruit during development and ripening. Plant Physiol. 118:1295-1305.

Nakatsuka, A., S. Shiomi, Y. Kubo, and A. Inaba. 1997. Expression and internal feedback regulation of ACC synthase and ACC oxidase genes in ripening tomato fruit. Plant Cell Physiol. 38:1103-1110.

Nanthachai, N., B. Ratanachinakorn, M. Kosittrakun, and R.M. Beaudry. 2007. Absorption of 1-MCP by fresh produce. Postharvest Biol. Technol. 43:291-297.

Nehring, R.B. and J.R. Ecker. 2004. Ethylene responses in seedling growth and development, p. 350-368. In: P.J. Davies (ed.). Plant hormones: Biosynthesis, signal transduction, action. Kluwer Academic Publishers, Norwell, MA.

Oetiker, J.H., D.C. Olson, O.Y. Shiu, and S.F. Yang. 1997. Differential induction of seven 1-aminocylcopropane-1-carboxylate synthase genes by elicitor in suspension cultures of tomato (Lycopersicon esculentum). Plant Mol. Biol. 34:275-286.

Patterson, S.E. and A.B. Bleecker. 2004. Ethylene-dependent and -independent processes associated with floral organ abscission in arabidopsis. Plant Physiol. 134:194-203.

Peck, S.C. and H. Kende. 1998. Differential expression of genes encoding 1-aminocyclopropane-1-carboxylate (ACC) synthase in etiolated pea seedlings: Effects of indole-3-acetic acid, wounding, and ethylene. Plant Mol. Biol. 38:977-982.

Perry, S.C. and T.J. Gianfagna. 1987. Effect of silaid and Ethrel on peach leaf and fruit abscission in relation to the kinetics of ethylene release. Acta Hort. 201:157-163.

Pesis, E., M. Ackerman, R. Ben-Aire, O. Feygenberg, X. Feng, A. Apelbaum, R. Goren, and D. Prusky. 2002. Ethylene involvement in chilling injury symptoms of avocado during cold storage. Postharvest Biol. Technol. 24:171-181.

Pozo, L., R. Yuan, I. Kostenyuk, F. Alférez, G.Y. Zhong, and J.K. Burns. 2004. Differential effects of 1-methylcyclopropene on citrus leaf and mature fruit abscission. J. Amer. Soc. Hort. Sci. 129:473-478.
Rasori, A., B. Ruperti, C. Bonghi, P. Tonutti, and A. Ramina. 2002. Characterization of two putative ethylene receptor genes expressed during peach fruit development and abscission. J. Expt. Bot. 53: 2333-2339.

Ratner, A., R. Goren, and S.P. Monselise. 1969. Activity of pectin esterase and cellulase in the abscission zone of citrus leaf explants. Plant Physiol. 44:1717-1723.

Reid, M.S., B. Wollenweber, and M. Serek. 2002. Carbon balance and ethylene in the postharvest life of flowering hibiscus. Postharvest Biol. Technol. 25:227-233.

Roman, G., B. Lubarsky, J.J. Kieber, M. Rothenberg, and J.R. Ecker. 1995. Genetic analysis of ethylene signal transduction in Arabidopsis thaliana: Five novel mutant loci integrated into a stress response pathway. Genetics 139:1393-1409.

Sakai, H., J. Hua, Q.G. Chen, C. Chang, L.J. Medrana, A.B. Bleecker, and E.M. Meyerowitz. 1998. ETR2 is an ETR1-like gene involved in ethylene signaling in arabidopsis. Proc. Natl. Acad. Sci. USA 95:5812-5817.

Sexton, R., G. Laird, and W.G. van Doorn. 2000. Lack of ethylene involvement in tulip tepal abscission. Physiol. Plant. 108:321-329.

Tanase, K., T. Onozaki, S. Satoh, M. Shibata, and K. Ichimura. 2008. Differential expression levels of ethylene biosynthetic pathway genes during senescence of long-lived carnation cultivars. Postharvest Biol. Technol. 47:210-217.

Tieman, D.M. and H.J. Klee. 1999. Differential expression of two novel members of the tomato ethylene-receptor family. Plant Physiol. 120:165-172.

Tieman, D.M., J.A. Ciardi, M.G. Taylor, and H.J. Klee. 2001. Members of the tomato LeEIL (EIN3-like) gene family are functionally redundant and regulate ethylene responses throughout plant development. Plant J. 26:47-58.

Tieman, D.M., M.G. Taylor, J.A. Ciardi, and H.J. Klee. 2000. The tomato ethylene receptors NR and LeETR4 are negative regulators of ethylene response and exhibit functional compensation within a multigene family. Proc. Natl. Acad. Sci. USA 97:5663-5668.

University of California. 2009. HarvEST: Citrus version 1.25. 11 June 2009. <http://harvest.ucr.edu/>.

van Doorn, W.G. 2002. Effect of ethylene on flower abscission: A survey. Ann. Bot. (Lond.) 89:689-693.

von Heijne, G. 1992. Membrane protein structure prediction. Hydrophobicity analysis and the positive-inside rule. J. Mol. Biol. 225: 487-494

Wagstaff, C., U. Chanasut, F.J.M. Harren, L.-J. Laarhoven, B. Thomas, H.J. Rogers, and A.D. Stead. 2005. Ethylene and flower longevity in Alstroemeria: Relationship between tepal senescence, abscission and ethylene biosynthesis. J. Expt. Bot. 56:1007-1016.

Wang, W., A.E. Hall, R. O'Malley, and A.B. Bleecker. 2003. Canonical histidine kinase activity of the transmitter domain of the ETR1 ethylene receptor from arabidopsis is not required for signal transmission. Proc. Natl. Acad. Sci. USA 100:352-357.

Whitelaw, C.A., N.N. Lyssenko, L. Chen, D. Zhou, A.K. Mattoo, and M.L. Tucker. 2002. Delayed abscission and shorter internodes correlated with a reduction in the ethylene receptor LeETRI transcript in transgenic tomato. Plant Physiol. 128:978-987.

Wilkinson, J.Q., M.B. Lanahan, H.-C. Yen, J.J. Giovannoni, and H.J. Klee. 1995. An ethylene-inducible component of signal transduction encoded by never-ripe. Science 270:1807-1809.

Wills, R.B.H. and V.V.V. Ku. 2002. Use of 1-MCP to extend the time to ripen of green tomatoes and postharvest life of ripe tomatoes. Postharvest Biol. Technol. 26:85-90.

Xu, S.-L., A. Rahman, T.I. Baskin, and J.J. Kieber. 2008. Two leucinerich repeat receptor kinases mediate signaling, linking cell wall biosynthesis and ACC synthase in arabidopsis. Plant Cell 20:30653079.

Yuan, R., Z. Wu, I.A. Kostenyuk, and J.K. Burns. 2005. G-proteincoupled $\alpha_{2 A}$-adrenoreceptor agonists differentially alter citrus leaf and fruit abscission by affecting expression of ACC synthase and ACC oxidase. J. Expt. Bot. 56:1867-1875. 